\title{
Genetic characterization of measles virus in the Philippines, 2008-2011
}

Rex Centeno ${ }^{1}$, Naoko Fuji ${ }^{2}$, Michiko Okamoto ${ }^{2}$, Clyde Dapat ${ }^{2}$, Mariko Saito ${ }^{2,3}$, Amado Tandoc ${ }^{1}$, Socorro Lupisan ${ }^{1}$ and Hitoshi Oshitani ${ }^{2,3^{*}}$

\begin{abstract}
Background: Large outbreaks of measles occurred in the Philippines in 2010 and 2011. Genetic analysis was performed to identify the genotype of measles virus (MeV) that was responsible for the large outbreaks.

Methods: A total of 114 representative MeVs that were detected in the Philippines from 2008 to 2011 were analyzed by sequencing the $\mathrm{C}$-terminal region of nucleocapsid $(\mathrm{N})$ gene and partial hemagglutinin $(\mathrm{H})$ gene and by inferring the phylogenetic trees.

Results: Genetic analysis showed that genotype D9 was the predominant circulating strain during the 4-year study period. Genotype D9 was detected in 23 samples (92\%) by N gene sequencing and 93 samples (94\%) by H gene analysis. Sporadic cases of genotype G3 MeV were identified in 2 samples (8\%) by N gene sequencing and 6 samples (6\%) by H gene analysis. Genotype G3 MeV was detected mainly in Panay Island in 2009 and 2010. Molecular clock analysis of $\mathrm{N}$ gene showed that the recent genotype D9 viruses that caused the big outbreaks in 2010 and 2011 diverged from a common ancestor in 2005 in one of the neighboring Southeast Asian countries, where D9 was endemic. These big outbreaks of measles resulted in a spillover and were associated with genotype D9 MeV importation to Japan and the USA.

Conclusion: Genotype D9 MeV became endemic and caused two big outbreaks in the Philippines in 2010 and 2011. Genotype G3 MeV was detected sporadically with limited geographic distribution. This study highlights the importance of genetic analysis not only in helping with the assessment of measles elimination program in the country but also in elucidating the transmission dynamics of measles virus.
\end{abstract}

Keywords: Measles, Genotyping, Molecular epidemiology, Molecular clock analysis

\section{Background}

The measles virus $(\mathrm{MeV})$ is a highly contagious pathogen, which causes a disease in humans characterized by prodromal symptoms that include high fever, cough, runny nose, conjunctivitis, and tiny white spots on the inside of the mouth before the onset of rash [1]. MeV belongs to order Mononegavirales, family Paramyxoviridae, genus Morbillivirus and contains nonsegmented singlestranded RNA genome of negative polarity that is $16 \mathrm{~kb}$ in length [2]. The genome codes for six viral proteins

\footnotetext{
*Correspondence: oshitanih@med.tohoku.ac.jp

${ }^{2}$ Department of Virology, Graduate School of Medicine, Tohoku

University, 2-1 Seiryo-machi, Aoba-ku, Sendai, Miyagi Prefecture 980-8575,

Japan

Full list of author information is available at the end of the article
}

namely; hemagglutinin $(\mathrm{H})$ and fusion $(\mathrm{F})$ glycoproteins, matrix $(\mathrm{M})$ protein, nucleocapsid $(\mathrm{N})$ protein, phosphoprotein $(\mathrm{P})$, and large polymerase $(\mathrm{L})$ protein [2]. The $\mathrm{C}$-terminal hypervariable region of the $\mathrm{N}$ gene $(\mathrm{N}-450)$ or the full length $\mathrm{H}$ gene is used in the genetic characterization of $\mathrm{MeV}$ and monitoring of measles control programs [3]. To standardize the nomenclature of $\mathrm{MeV}$, the World Health Organization (WHO) established a systematic classification of the genetic characteristics of wild-type viruses [4].

Vaccination remains the first line of defense for measles virus infection. Before the introduction of measles vaccine in the 1960 s, the disease was responsible for millions of deaths per year worldwide [1]. In the Philippines, the monovalent measles vaccine was introduced in 1983 
and the trivalent vaccine composed of measles, mumps, rubella (MMR) was introduced in 1990 [5]. Supplementary immunization activities (SIAs) were conducted in the country in 1998 (coverage 85\%); 2004 (95\%); 2007 (95\%), and 2011 (84\%) [5]. Before the introduction of nationwide mass measles vaccination campaign in the Philippines, the estimated deaths among children caused by measles was about 6,000 [6].

To measure the country's progress towards measles elimination and monitor the effectiveness of mass vaccination campaigns, regular surveillance is carried out by the Department of Health. Laboratory confirmation of suspected measles cases is conducted at the Research Institute for Tropical Medicine (RITM) in Metro Manila by detecting measles-specific IgM antibody [7]. However, genetic analysis is not performed routinely so there is limited information on the current circulating strains. Previous reports showed that the number of measles was reduced in 2005, after a nationwide mass vaccination campaign in 2004 [6], and genetic analysis of samples collected between 2000 and early 2008 showed that the circulation of an endemic D3 genotype was interrupted and was replaced by an imported D9 genotype in 2007 [8]. However, measles outbreak were reported in the Philippines in 2010 and 2011 [5]. This study was conducted to determine if a new genotype was responsible for the measles outbreaks in 2010 and 2011. This study also aimed to characterize the molecular evolution and geographic distribution of genotypes of measles virus in the Philippines.

\section{Results}

\section{Epidemiology of measles in the Philippines}

The number of reported confirmed cases and incidence of measles in the Philippines from 2008 to 2011 were obtained from the WHO regional and country profiles of measles elimination report (Figure 1) [5]. Significant increase of measles cases was reported in the Philippines in 2010 and 2011, which showed a 7-fold increase in the incidence rate of 69.1 per 1 million population in 2011, when compared with the data in 2008. The number of deaths attributed to measles also increased from 8 deaths in 2008 to 28 deaths in 2011 [5].

During the study period, a total of 7,437 IgM ELISApositive samples were collected at RITM and of these, 565 samples were selected and tested for PCR assay using primers specific for the $\mathrm{N}$ and $\mathrm{H}$ genes (Table 1). Results showed that of the 114 samples that were tested positive by PCR, 25 and 99 samples were positive for $\mathrm{N}$ and $\mathrm{H}$ genes respectively.

\section{Phylogenetic analysis of $\mathrm{MeV}$ in the Philippines}

Phylogenetic analysis of the 450-nt C-terminal hypervariable region of $\mathrm{N}$ gene showed that the 2008-2011 MeVs

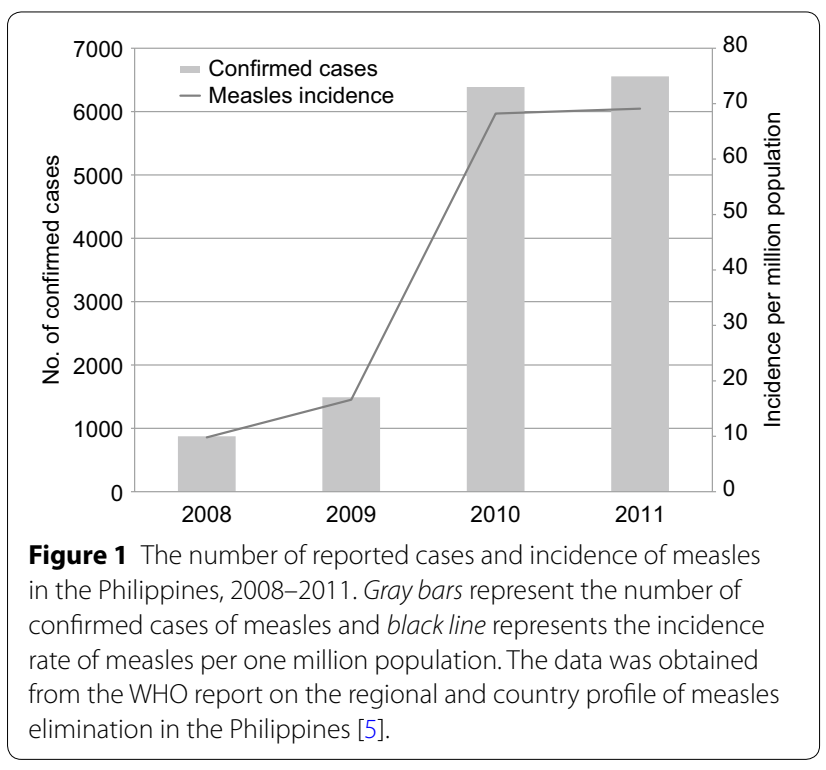

Table 1 Yearly distribution of IgM ELISA and PCR positive samples and genotypes of measles virus in the Philippines

\begin{tabular}{lrrrrr}
\hline & $\mathbf{2 0 0 8}^{\mathbf{a}}$ & $\mathbf{2 0 0 9}$ & $\mathbf{2 0 1 0}$ & $\mathbf{2 0 1 1}$ & Total \\
\hline IgM ELISA positive & 120 & 698 & 2,973 & 3,646 & 7,437 \\
Number of PCR samples tested & 16 & 65 & 228 & 256 & 565 \\
H gene PCR positive & 3 & 13 & 53 & 30 & 99 \\
N gene PCR positive & 2 & 5 & 9 & 9 & 25 \\
D9 genotype & 2 & 9 & 51 & 29 & 91 \\
G3 genotype & 1 & 3 & 2 & 0 & 6 \\
Undetermined genotype & 0 & 1 & 0 & 1 & 2
\end{tabular}

a Data from July 2008.

in the Philippines belonged to two genotypes, D9 and G3 (Figure $2 \mathrm{a}$ ). Of the 25 representative $\mathrm{N}$ gene sequences analyzed, 23 samples (92\%) clustered with the genotype D9 reference strain ( $92 \%$ bootstrap value) and 2 samples (8\%) clustered with the genotype G3 reference strain (87\% bootstrap value). Similar clustering was observed using the Bayesian Markov chain Monte Carlo (MCMC) method with posterior probability values of 1.0 and 0.99 for genotypes D9 and G3 respectively (Additional file 1: Figure S1). The two cases of genotype G3 in the Philippines formed a separate group and did not cluster with $\mathrm{MeVs}$ from other countries.

Pairwise distance analysis of $\mathrm{N}$ gene showed high sequence similarity between Philippine strains and reference strains from other countries (Additional file 2: Table S1). Three Philippine strains (Batangas/PHL/10.11, Zamboanga del Sur/PHL/49.10, Manila/PHL/39.10) exhibited $100 \%$ sequence similarity with 1 strain in Canada (Saskatchewan.CAN/40.11), 1 strain in the USA (Texas. USA/5.11), and 6 strains in Japan (2010-2011). Another 


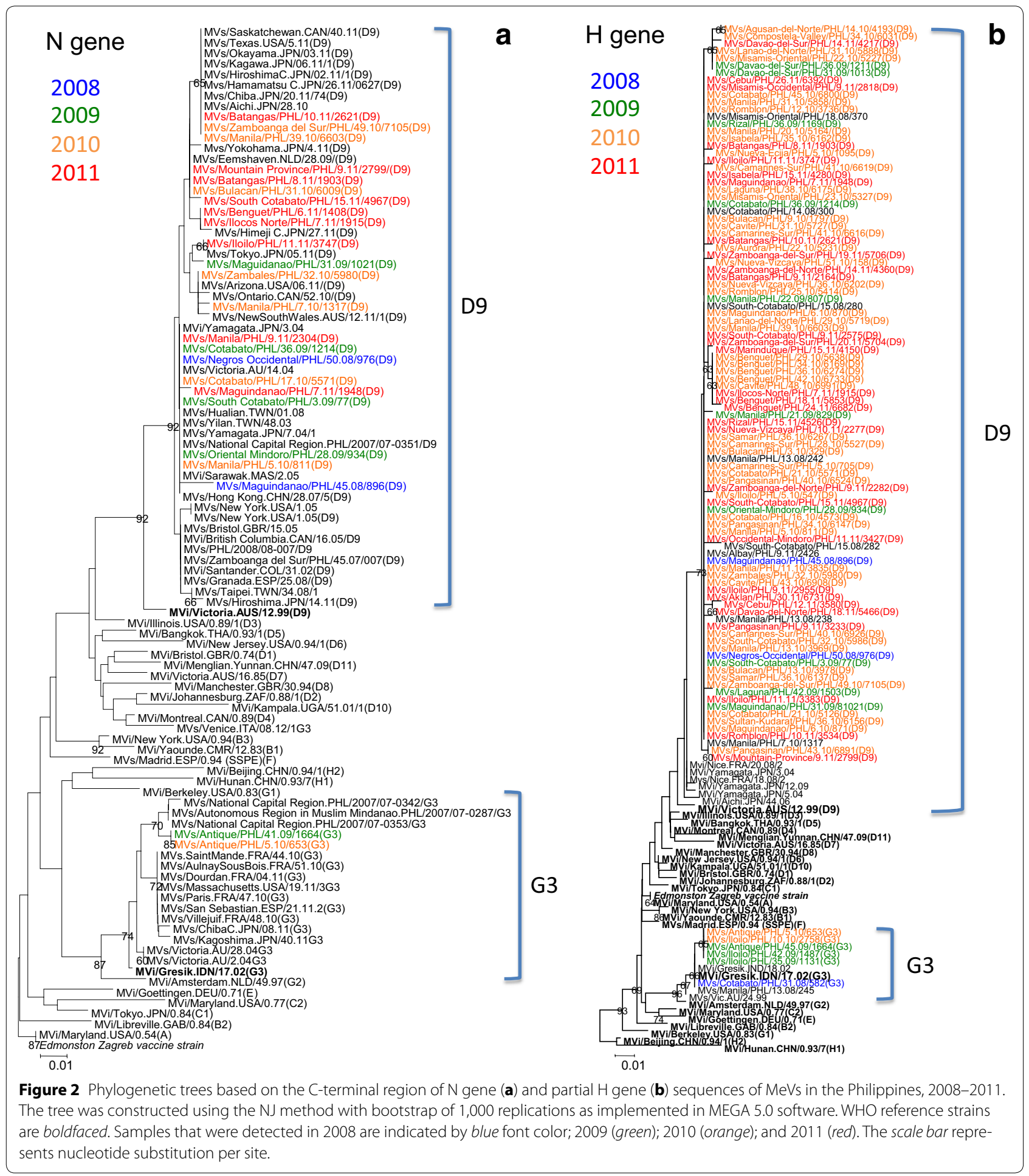

three Philippine strains (Mountain Province/PHL/9.11, Batangas/PHL/8.11, Bulacan/PHL/31.10) showed high sequence similarity with $\mathrm{MeV}$ from the Netherlands (Eemshaven/NLD/28.09). One strain from central Philippines (Iloilo/PHL/11.11) showed high sequence identity with a strain from Japan (Tokyo.JPN/05.11). One strain from Luzon (Zambales/PHL/32.10) showed $100 \%$ sequence similarity with a strain from the USA (Arizona.USA/06.11). Eight Philippine strains showed high sequence similarity with older $\mathrm{MeV}$ viruses from 
Taiwan (2003), Japan (2004), Australia (2004), and Malaysia (2005). Two Philippine strains showed high sequence similarity with MeVs from Columbia (2002), UK (2005), Canada (2005), and Spain (2008). In 2010 and 2011, a total of 4 cases of genotype D9 virus infection in Japan and 6 cases in the USA showed clear epidemiological link to the MeV infections in the Philippines [9-11].

Phylogenetic analysis of MeVs that were detected in the Philippines from 2008 to 2011 showed that the partial H gene phylogeny was congruent with the $\mathrm{N}$ gene phylogeny in the NJ method (Figure $2 \mathrm{~b}$ ) and MCMC method (Additional file 3: Figure S2). Of the 99 representative $\mathrm{H}$ gene sequences analyzed, 93 samples (94\%) grouped together with the genotype D9 reference strain (73\% bootstrap value) and 6 samples (6\%) grouped together with the genotype G3 reference strain ( $96 \%$ bootstrap value).

Analysis of the partial $\mathrm{H}$ gene sequence of the 6 cases of genotype G3 MeVs in the Philippines showed similar clustering with the $\mathrm{N}$ gene phylogeny (Figure 2b). Within the G3 cluster, one sample (MVs/Cotabato/ PHL/31.08/582) grouped with the sample that was detected in Manila in early 2008 and the remaining five samples that were detected in 2009 and 2010 formed another separate group.

Mapping of the geographic location of measles cases in the Philippines according to genotype showed that the cases of genotype $\mathrm{D} 9 \mathrm{MeVs}$ were detected in all 16 regions in the country (Figure 3a-d). One case of genotype G3 was detected in Mindanao in 2008 (Figure 3a) and the remaining five cases of G3 were detected mainly in the island of Panay (Region 6) in 2009 (Figure 3b) and in 2010 (Figure 3c). Both genotypes D9 and G3 were detected in Panay Island in 2010, however, only genotype D9 MeV continued to circulate in the following year and G3 MeVs were not detected in 2011. Some groups with identical sequences (e.g. MVs/Lanao-del-Norte/PHL/31.10/5888, MVs/Misamis-Oriental/PHL/22.10/5227, MVs/ Davao-del-Sur/PHL/36.09/1211, MVs/Davao-del-Sur/ PHL/31.09/1013) showed geographic clustering, while other groups with identical sequences (e.g. MVs/Cotabato/PHL/45.10/6800, MVs/Manila/PHL/31.10/5858, MVs/Romblon/PHL/12.10/3736) were detected in different islands within the country (Additional file 4: Table S2; Figure 3b, c).

\section{Molecular evolution of $\mathrm{MeV}$ in the Philippines}

The molecular evolution of the $\mathrm{N}$ gene of the MeVs in the Philippines was analyzed using MCMC method. Results showed that the mean nucleotide substitution rate of $\mathrm{N}$ gene is $2.78 \times 10^{-3}$ [95\% highest posterior density (HPD) interval: $7.2 \times 10^{-4}$ to $4.96 \times 10^{-3}$ ] substitutions per site per year, which was estimated using the uncorrelated lognormal relaxed clock-constant population growth model combination that was determined as the best-fitting model (Table 2). These estimates are similar to previously reported mean mutation rates of $\mathrm{MeV}$ in Spain: $3.0 \times 10^{-3}$ substitutions/site/year for genotype $\mathrm{C} 2 \mathrm{MeV}$ from 1992 to $1993 ; 5.0 \times 10^{-4}$ substitutions/site/year for genotype D6 from 1993 to 1996 [12]; and $2.66 \times 10^{-3}$ substitutions/site/year for genotype B3 MeV in 2006 [13]. Similar estimate was also reported for genotype $\mathrm{H} 1 \mathrm{MeV}$ in China, from 1993 to 2012 with $1.65 \times 10^{-3}$ substitutions/site/year [14]. Analysis of $\mathrm{N}$ gene sequences available in GenBank showed similar mutation rate of $8.69 \times 10^{-4}$ substitutions/site/year [15]. The mean time to the most recent common ancestor (tMRCA) for genotype D9 MeVs in the Philippines is August 2005 [95\% HPD: September 2001 to November 2007] and the tMRCA for genotype G3 is May 2008 [95\% HPD: September 2007 to August 2008] (Table 2).

MCC trees showed similar clustering of Philippine D9 and G3 genotypes by four different models, which is in agreement with the NJ distance method. Within D9 genotype, MeVs in the Philippines shared common ancestors with viruses from Colombia (MVi/Santander.COL/31.02) (group 1), Taiwan (MVs/Yilan/TWN/48.03) (group 2), Australia (MVs/Victoria.AU/14.04) (group 3), Malaysia (MVi/Sarawak.MAS/2.05) (group 4) (Additional file 1: Figure S1). Bayesian skyline plot analysis of $\mathrm{H}$ gene of genotype $\mathrm{D} 9 \mathrm{MeV}$ in the Philippines showed an increase in genetic diversity in 2010 and peaked in 2011 (Additional file 5: Figure S3).

\section{Discussion}

Large outbreaks of measles were reported in the Philippines in 2010 and 2011 [5]. Genetic analysis showed that genotype $\mathrm{D} 9 \mathrm{MeV}$ was responsible for these large outbreaks in the country. From 2000 to 2004, genotype D3 was endemic in the Philippines [8]. The transmission of endemic genotype D3 MeVs was interrupted after a mass vaccination campaign in $2004[6,8]$. Since 2005, genotype D3 has not been detected in countries belonging to the WHO Western Pacific Region [16]. In 2007, sporadic cases of genotypes D9 and G3 virus infections were detected in the country [8]. In this report, genotype D9 became the predominant strain in the Philippines in 2010 and 2011.

Genotype D9 was described first in Australia in 1999, which was an imported case from Indonesia [17]. Outbreaks of genotype D9 in Indonesia and Malaysia during the same period may suggest that D9 was endemic in these countries [17]. In 2002, a large measles outbreak occurred in Venezuela and spread to Colombia, where the index case developed measles after returning from a trip to Europe [18]. Sequence analysis revealed a close 


\section{a} 2008

- one D9 MeV case

- one $\mathrm{G} 3 \mathrm{MeV}$ case

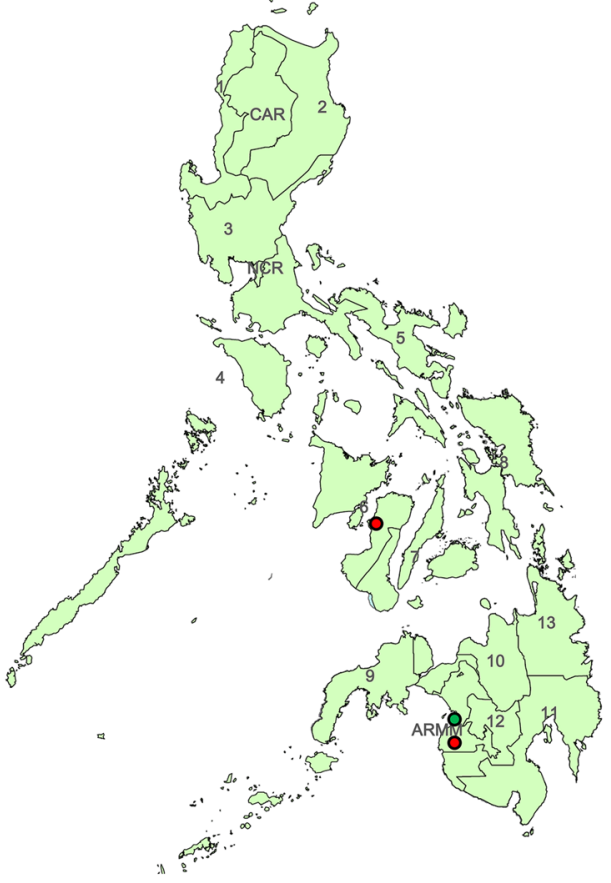

c

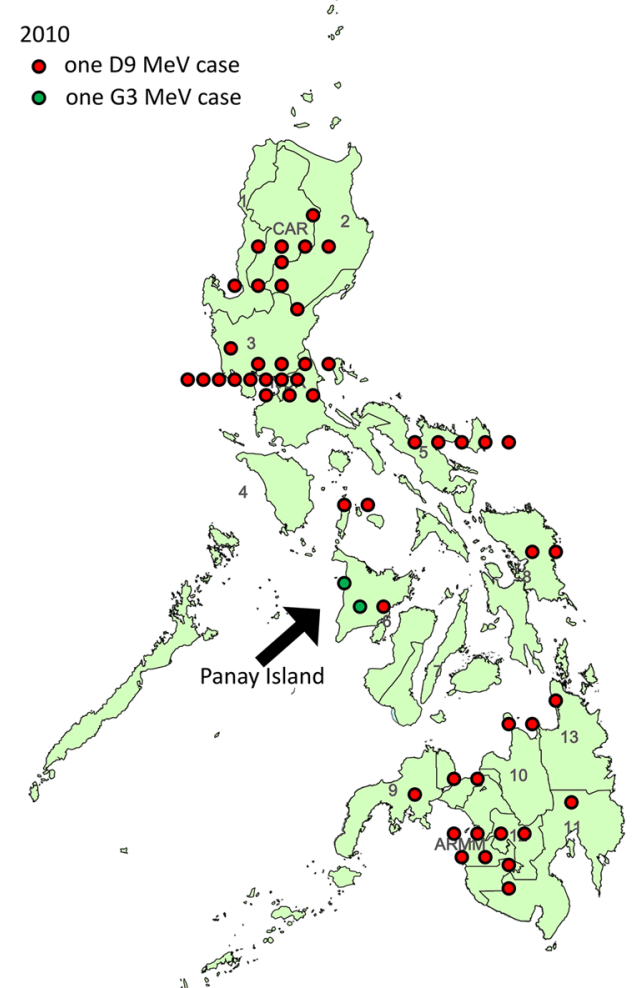

b 2009

- one D9 MeV case

- one G3 MeV case $a^{\circ}$
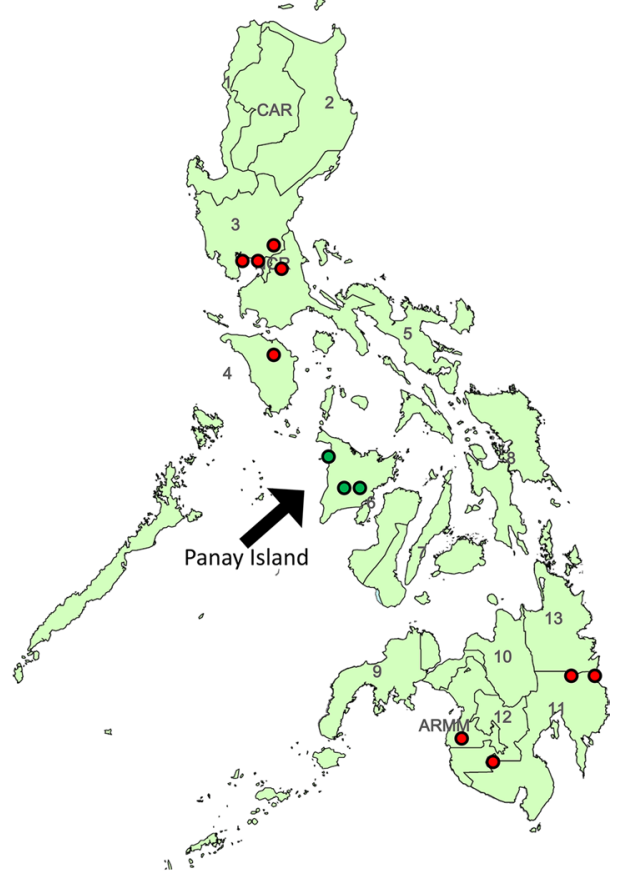

d 2011

- one D9 MeV case

0 one G3 MeV case $0^{\circ}$

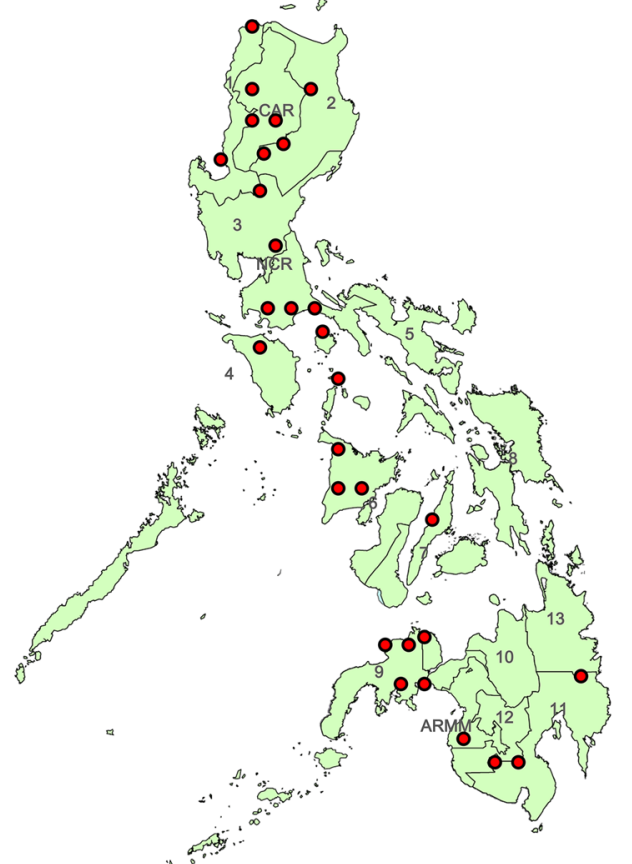

Figure 3 Geographic distribution of genotypes D9 and G3 in the Philippines. Distribution of genotypes D9 (red circle) and G3 (green circle) in 2008 (a), 2009 (b), 2010 (c), and 2011 (d). One circle represents one case of MeV infection. Numbers represent the different administrative regions in the country. CAR Cordillera Autonomous Region, NCR National Capital Region, ARMM Autonomous Region in Muslim Mindanao. 
Table 2 The estimated substitution rates and the dates of most recent common ancestor by four different models

\begin{tabular}{|c|c|c|c|c|}
\hline Molecular clock & Demographic model & $\begin{array}{l}\text { Substitution rate }{ }^{a}, \times 10^{-3} \\
(95 \% \text { HPD) }\end{array}$ & tMRCA, D9 (95\% HPD) & tMRCA, G3 (95\% HPD) \\
\hline Strict & Constant & $2.54(0.96-4.35)$ & $\begin{array}{l}2005 \text { September } 20 \text { (2002 May to } \\
2007 \text { Nov) }\end{array}$ & $\begin{array}{l}2008 \text { May } 18 \text { (2007 Oct to } 2008 \\
\text { Aug) }\end{array}$ \\
\hline Strict & Exponential growth & $2.71(1.10-4.47)$ & $\begin{array}{l}2006 \text { January } 12 \text { (2003 Mar to } 2007 \\
\text { Nov) }\end{array}$ & $\begin{array}{l}2008 \text { May } 29 \text { (2007 Nov to } 2008 \\
\text { Aug) }\end{array}$ \\
\hline Lognormal relaxed & Constant & $2.78(0.72-4.96)$ & $\begin{array}{l}2005 \text { August } 3 \text { (2001 Sept to } 2007 \\
\text { Nov) }\end{array}$ & $\begin{array}{l}2008 \text { May } 15 \text { (2007 Sept to } 2008 \\
\text { Aug) }\end{array}$ \\
\hline Lognormal relaxed & Exponential growth & $3.37(0.92-6.23)$ & $\begin{array}{l}2006 \text { January } 20 \text { (2003 Jan to } 2007 \\
\text { Nov) }\end{array}$ & $\begin{array}{l}2008 \text { May } 24 \text { (2007 Oct to } 2008 \\
\text { Aug) }\end{array}$ \\
\hline
\end{tabular}

tMRCA time to the most recent common ancestor, HPD highest posterior density interval.

a Substitutions/site/year.

match with the imported $\mathrm{MeV}$ in Australia in 1999 [18]. In 2004, a measles outbreak occurred in a junior high school in Japan that was caused by genotype D9, which has not been detected previously in the country $[19,20]$. Genetic analysis also showed a high sequence similarity with the $1999 \mathrm{MeV}$ in Australia that was imported from Indonesia [19].

Before 2005, genotype D9 was not detected in the Philippines. $\mathrm{D} 9 \mathrm{MeV}$ infections in this period were associated with imported cases from Indonesia, East Timor, Malaysia, and Singapore where D9 was endemic $[8,16]$. Notably, eight D9 MeVs that were collected from 2008 to 2011 exhibited high sequence similarity with MeVs in Malaysia in 2005. In addition, molecular clock analysis suggests that the recent genotype D9 viruses that caused the big outbreaks in 2010 and 2011 diverged from a common ancestor in 2005. These findings suggest that genotype D9 $\mathrm{MeV}$ was imported to the Philippines from neighboring countries around 2005.

Genotype $\mathrm{D} 9 \mathrm{MeV}$ was detected at an increasing rate in the Philippines since 2007. It has replaced the earlier endemic genotype G3 strain and became the predominant genotype. The increasing prevalence of $\mathrm{D} 9 \mathrm{MeV}$ has been detected in Taiwan, Thailand, and other neighboring countries $[16,21,22]$. In our previous study, the sequences of genotype D9 viruses that were detected in the Philippines in 2007 and 2008 shared high sequence similarity to those in Hong Kong (2007) and Taiwan (2003 and 2008) [8]. Of particular note, the genotype D9 cases in Taiwan in 2003 and 2008 were imported cases from Japan and the Philippines, respectively [23]. In this study, genotype D9 was the predominant strain in the country from July 2008 to 2011 . Our data suggests that D9 $\mathrm{MeV}$ was responsible for the two big measles outbreak in 2010 and 2011.

The diversity of genotype D9 MeVs in the Philippines may be attributed to a combination of multiple importations and sustained local transmission. At least 4 importations of D9 genotype MeVs were observed in the
Philippines, which shared common ancestors with $\mathrm{MeVs}$ from Colombia (MVi/Santander.COL/31.02) (group 1), Taiwan (MVs/Yilan/TWN/48.03) (group 2), Australia (MVs/Victoria.AU/14.04) (group 3), Malaysia (MVi/ Sarawak.MAS/2.05) (group 4) (Additional file 1: Figure S1). During the big outbreaks in 2010 and 2011, group 3 and 4 viruses were cocirculating in the Philippines. Bayesian skyline plot analysis showed an increase in genetic diversity in 2010 and peaked in 2011 (Additional file 5: Figure S3), which suggests that endemic transmission of group 3 and $4 \mathrm{MeVs}$ contributed to genetic diversity.

A limitation of this study is the use of partial $\mathrm{H}$ gene sequence for genotyping analysis. The WHO recommends the use of full $\mathrm{H}$ gene for genotyping [16]. However, only partial $\mathrm{H}$ gene sequences were obtained in this study because the samples used were from patients' sera and not from virus isolates. Patients' sera may contain low quality and insufficient amount of viral RNA. Despite this limitation, the $\mathrm{H}$ gene analysis was in agreement with $\mathrm{N}$ gene phylogeny and showed clustering of Philippines samples together with the D9 genotype reference strain and validated using two methods with a high bootstrap value of $92 \%$ for the $\mathrm{NJ}$ method and a posterior probability of 1.0 for the MCMC method. $\mathrm{H}$ gene analysis corroborated the findings of $\mathrm{N}$ gene phylogeny, which showed that the recent large outbreaks of measles in the Philippines were caused by $\mathrm{D} 9$ genotype $\mathrm{MeV}$ that has become established and sustained its transmission among susceptible populations. Sustained local transmission of D9 genotype $\mathrm{MeV}$ was supported by geographic clustering of viruses with identical sequences. This sustained transmission of $\mathrm{MeVs}$ in different regions of the Philippines often caused a spillover and it is associated with $\mathrm{MeV}$ importation to other countries. In Japan and the USA, imported cases of D9 MeV from the Philippines were documented and reported in 2010 and 2011 [9-11]. 
Another limitation of this study is the lack of historical support for tMRCA and mutation rate estimates. Comparison of our estimates to previously reported mean substitution rates showed similar results with MeVs in Spain, China, and other countries [12-15]. Our estimates were relatively lower but overlapped with the mutation rates of other RNA viruses such as human metapneumovirus [24] and influenza A virus [25]. This suggests that $\mathrm{MeVs}$, like most RNA viruses exhibit high mutation rates, short generation times, and large population sizes due to its high reproductive number [24].

Genotype D9 measles virus was not the only strain that was circulating in the Philippines from 2008 to 2011. Sporadic cases of genotype G3 MeVs were detected from July 2008 to March 2010. Genotype G3 was reported first in 1999 in Australia, where this genotype was associated with local outbreaks and importation from East Timor [26]. In 2002, genotype G3 was isolated in East Timor and Indonesia, where this genotype was found to be endemic [27]. In the Philippines, genotype G3 was detected first in 2007 and cocirculated with genotype D9 [8]. While genotype D9 was detected in all regions in the country, genotype G3 circulation was limited only in Mindanao in late 2008 and in Panay Island in 2009 and 2010. Genotypes D9 and G3 cocirculated in Panay Island in 2010 but only D9 was detected in the following year. Phylogenetic and tMRCA analyses suggest that genotype $\mathrm{G} 3 \mathrm{MeV}$ might be imported from East Timor and Indonesia, where G3 and D9 MeVs are endemic [16, 26]. Continued surveillance must be performed to determine if the G3 genotype would reemerge in the Philippines.

\section{Conclusion}

Genetic analysis showed that genotype D9 was responsible for the large measles outbreaks in the Philippines in 2010 and 2011. Genetic analysis revealed that genotype D9 virus became endemic in the country. Genotype G3 $\mathrm{MeV}$ was detected sporadically and its circulation occurred only in limited geographic parts of the country. This study highlights the importance of genetic analysis in helping with the assessment of measles elimination program in the country. This study underscores the need for continued high measles vaccination coverage to minimize the number of susceptible population, stop the transmission of endemic MeVs, prevent importation of MeVs in other countries, and meet the goal of measles elimination in the Philippines. This study provides important genetic surveillance data that can help monitor the progress of measles elimination in the country and help establish the transmission route of $\mathrm{MeVs}$ in the region and other parts of the world.

\section{Methods}

\section{Clinical samples}

A total of 565 serum samples that were tested positive for measles-specific IgM antibody were selected in this study. These samples were collected from suspected measles cases from different parts of the country and were sent to RITM for ELISA-based testing for anti-measles IgM antibodies [7]. At least one sample per month and per region was randomly selected from July 2008 to November 2011. Only samples that were collected within 3 days from onset of rash were included in this study. This study was approved by the Ethics Committee of Tohoku University Graduate School of Medicine and the Institutional Review Board (IRB) of RITM. Written informed consent was obtained from patients or patients' parents or guardians before samples were collected.

\section{RNA extraction and RT-PCR}

Total RNA was extracted directly from serum samples using the PureLink Viral RNA/DNA MiniKit (Invitrogen, Carlsbad, CA). RT-PCR was performed using One-Step RT-PCR kit (Qiagen, Hilden, Germany). Gene-specific primers were utilized to amplify the C-terminal region of the $\mathrm{N}$ gene (456 nt) and partial $\mathrm{H}$ gene (309 nt) using conventional PCR and nested PCR protocols as described previously $[28,29]$.

\section{Sequencing and phylogenetic analyses}

PCR products were purified using SUPRIC ${ }^{\mathrm{TM}}-\mathrm{PCR}$ (TaKaRa, Otsu, Japan) kit. Direct sequencing of PCR product was performed using BigDye Terminator v3.1 Cycle Sequencing Kit (Applied Biosystems, Foster City, CA, USA). Sequencing products were analyzed using the ABI Genetic Analyzer 3130 (Applied Biosystems, Foster City, CA, USA).

Phylogenetic analysis was performed using the neighbor-joining (NJ) method in Molecular Evolution Genetic Analysis (MEGA) software 5.0 [30]. Statistical support was tested using the bootstrap method with 1,000 replicates and values $>60 \%$ were indicated on the branches. Sequences of reference strains for each genotype and sequences from other countries were downloaded from GenBank and were included in the phylogenetic analysis. Pairwise p-distance for each measles sequence was calculated using MEGA software 5.0.

To estimate the rate of evolution and the time to the most recent common ancestor (tMRCA) of $\mathrm{MeV}$ in the Philippines, a Bayesian Markov chain Monte Carlo (MCMC) method was used as implemented in the BEAST package 1.8.0 [31, 32]. For tMRCA analysis, only samples from the Philippines were included in the 
dataset. Sample collection dates were incorporated in the $\mathrm{N}$ gene sequence dataset to calibrate the molecular clock [33]. The best-fitting nucleotide substitution model was determined using the MEGA software 5.0 [30]. Based on the smallest Akaike information criterion (AIC) value, the Hasegawa-Kishino-Yano (HKY) model was selected as the best-fitting model [34]. The dataset was analyzed in BEAST using two different clock models (strict and uncorrelated lognormal relaxed) and two different demographic models (constant and exponential population growth) [35]. Results were compared to ensure that convergence was attained in each run and statistical summaries were combined after removing $10 \%$ as burn-in using the Tracer software in the BEAST package [31]. The best-fitting model for the dataset was determined by computing the Bayes factors using the Tracer software. Statistical uncertainties in the estimates were indicated by the $95 \%$ highest posterior density (HPD) intervals. Maximum clade credibility (MCC) trees were inferred also using the same $\mathrm{N}$ and $\mathrm{H}$ datasets in the NJ method for comparison of clustering of the Philippine samples with reference strains. Posterior probability values were indicated on the node of MCC trees. To estimate the genetic diversity of $\mathrm{MeV}$ overtime, a coalescent-based Bayesian skyline analysis was performed using the identified best-fitting clock and demographic models. Sequences described in this study were submitted to GenBank (N gene: KM066693-KM066717; H gene: KM 066718-KM066816).

\section{Additional files}

Additional file 1: Figure S1. Maximum clade credibility (MCC) tree of the $\mathrm{N}$ gene sequence of measles virus in the Philippines using the Bayesian Markov chain Monte Carlo (MCMC) method. X-axis represents the year of virus detection or isolation. Samples that were detected in 2008 are indicated by blue font color; 2009 (green); 2010 (orange); and 2011 (red). Genotype D9 MeVs are highlighted in blue box and genotype G3 viruses are highlighted in green box. Figures near the tree nodes represent posterior probability values. The scale bar represents nucleotide substitutions per site per year.

\section{Additional file 2: Table S1.}

Additional file 3: Figure S2. Maximum clade credibility (MCC) tree of the partial $\mathrm{H}$ gene sequence of measles virus in the Philippines using the Bayesian Markov chain Monte Carlo (MCMC) method. X-axis represents the year of virus detection or isolation. Samples that were detected in 2008 are indicated by blue font color; 2009 (green); 2010 (orange); and 2011 (red). Genotype D9 MeVs are highlighted in blue box and genotype $\mathrm{G} 3$ viruses are highlighted in yellow-green box. Figures near the tree nodes represent posterior probability values. The scale bar represents nucleotide substitutions per site per year.

Additional file 4: Table S2.

Additional file 5: Figure S3. Bayesian skyline plot of the $\mathrm{H}$ gene of genotype D9 MeVs in the Philippines. The estimate of the relative genetic diversity is plotted as a function of sample collection date. Thick black line represents the median value and light blue lines represent the high and low 95\% highest posterior densities (HPD).

\section{Authors' contributions}

$R C, N F, M O, A T, M S, S L$, and $H O$ conceived and designed the study. RC, NF, $\mathrm{MO}$, and AT established viral detection methods, and RC, NF, MS performed the test. $R C, N F, M O$, and $C D$ performed the genetic analysis. $C D$ drafted the manuscript with the assistance of NF, MO, AT, SL, and HO. All authors read and approved the final manuscript.

\section{Author details}

${ }^{1}$ Research Institute for Tropical Medicine (RITM), Alabang, Muntinlupa City, Philippines. ${ }^{2}$ Department of Virology, Graduate School of Medicine, Tohoku University, 2-1 Seiryo-machi, Aoba-ku, Sendai, Miyagi Prefecture 980-8575, Japan. ${ }^{3}$ Tohoku-RITM Collaborating Research Center for Emerging and Reemerging Infectious Diseases, Alabang, Muntinlupa City, Philippines.

\section{Acknowledgements}

We thank all the staff of the Tohoku-RITM Collaborating Research Center on Emerging and Reemerging Diseases. We acknowledge the Department of Health National Epidemiology Center Vaccine Preventable Disease Team and Regional Epidemiology Surveillance Units. We also thank the WHO Western Pacific Regional Office for their support in conducting measles surveillance. This study was supported by the Japan Initiative for Global Research Network on Infectious Diseases (J-GRID), Ministry of Education, Culture, Sports, Science and Technology (MEXT, Japan).

\section{Compliance with ethical guidelines}

\section{Competing interests}

The authors declare that they have no competing interests.

Received: 17 November 2014 Accepted: 20 May 2015

Published online: 03 June 2015

\section{References}

1. Moss WJ, Griffin DE (2012) Measles. Lancet 379:153-164

2. Knipe DM, Howley PM (2013) Fields virology, 6th edn. Wolters Kluwer/Lippincott Williams \& Wilkins Health, Philadelphia

3. Mulders MN, Truong AT, Muller CP (2001) Monitoring of measles elimination using molecular epidemiology. Vaccine 19:2245-2249

4. WHO (2012) WHO: Measles virus nomenclature update: 2012. Wkly Epidemiol Rec 87:73-81

5. WHO (2013) Country profile for measles elimination: Philippines. WHO Western Pacific Region

6. Sobel H, Ducusin J, De Quiroz M, Cabotaje M, Olive JM (2009) The Philippines 2004 measles campaign: a success story towards elimination. Trop Doct 39:36-38

7. WHO (2007) Manual for the laboratory diagnosis of measles and rubella virus infection, 2nd edn. World Health Organization

8. Fuji N, Suzuki A, Saito M, Centeno R, Galang H, Lupisan S et al (2011) Interruption of the circulation of an indigenous measles genotype and the introduction of other genotypes after a mass vaccination campaign in the Philippines. J Med Virol 83:1424-1427

9. National Institute of Infectious Diseases (2010) Infectious agents surveillance report. In: Book infectious agents surveillance report, 2010, Oct edition

10. National Institute of Infectious Diseases (2011) Infectious agents surveillance report. In: Book infectious agents surveillance report, 2011, Jan edition

11. Centers for Disease C, Prevention (2012) Measles_United States, 2011. MMWR Morb Mortal Wkly Rep 61:253-257

12. Rima BK, Earle JA, Baczko K, ter Meulen V, Liebert UG, Carstens $C$ et al (1997) Sequence divergence of measles virus haemagglutinin during natural evolution and adaptation to cell culture. J Gen Virol 78(Pt 1):97-106

13. Munoz-Alia MA, Fernandez-Munoz R, Casasnovas JM, Porras-Mansilla R, Serrano-Pardo A, Pagan I et al (2014) Measles virus genetic evolution throughout an imported epidemic outbreak in a highly vaccinated population. Virus Res 196C:122-127 
14. Xu S, Zhang Y, Rivailler P, Wang H, Ji Y, Zhen Z et al (2014) Evolutionary genetics of genotype $\mathrm{H} 1$ measles viruses in China from 1993 to 2012. J Gen Virol 95:1892-1899

15. Pomeroy LW, Bjornstad ON, Holmes EC (2008) The evolutionary and epidemiological dynamics of the paramyxoviridae. J Mol Evol 66:98-106

16. Rota PA, Brown K, Mankertz A, Santibanez S, Shulga S, Muller CP et al (2011) Global distribution of measles genotypes and measles molecular epidemiology. J Infect Dis 204(Suppl 1):S514-S523

17. Chibo D, Riddell M, Catton M, Lyon M, Lum G, Birch C (2003) Studies of measles viruses circulating in Australia between 1999 and 2001 reveals a new genotype. Virus Res 91:213-221

18. Centers for Disease C, Prevention (2002) Outbreak of measles-Venezuela and Colombia, 2001-2002. MMWR Morb Mortal Wkly Rep 51:757-760

19. Mizuta K, Abiko C, Murata T, Yamada K, Ahiko T, Sakamoto M et al (2005) An outbreak of measles virus infection due to a genotype D9 at a junior high school in Yamagata, Japan in 2004. Jpn J Infect Dis 58:98-100

20. Riddell MA, Rota JS, Rota PA (2005) Review of the temporal and geographical distribution of measles virus genotypes in the prevaccine and postvaccine eras. Virol J 2:87

21. Cheng WY, Tung HP, Wang HC, Lee LL, Wu HS, Liu MT (2013) Molecular epidemiology of measles virus in Taiwan in 2010-2011: the common genotype changed from $\mathrm{H} 1$ to D9 and the first appearance of D4. J Med Virol 85:1095-1099

22. Pattamadilok S, Incomserb P, Primsirikunawut A, Lukebua A, Rota PA Sawanpanyalert P (2012) Genetic characterization of measles viruses that circulated in Thailand from 1998 to 2008. J Med Virol 84:804-813

23. Cheng WY, Lee L, Rota PA, Yang DC (2009) Molecular evolution of measles viruses circulated in Taiwan 1992-2008. Virol J 6:219

24. de Graaf M, Osterhaus AD, Fouchier RA, Holmes EC (2008) Evolutionary dynamics of human and avian metapneumoviruses. J Gen Virol 89:2933-2942
25. Smith G, Vijaykrishna D, Bahl J, Lycett S, Worobey M, Pybus O et al (2009) Origins and evolutionary genomics of the 2009 swine-origin H1N1 influenza A epidemic. Nature 459:1122-1125

26. Chibo D, Riddell M, Catton M, Birch C (2002) Novel measles virus genotype, East Timor and Australia. Emerg Infect Dis 8:735-737

27. Rota PA, Bellini WJ (2003) Update on the global distribution of genotypes of wild type measles viruses. J Infect Dis 187(Suppl 1):S270-\$276

28. National Institute of Infectious Diseases (2003) Pathogen detection manual

29. Santibanez S, Tischer A, Heider A, Siedler A, Hengel H (2002) Rapid replacement of endemic measles virus genotypes. J Gen Virol 83:2699-2708

30. Tamura K, Peterson D, Peterson N, Stecher G, Nei M, Kumar S (2011) MEGA5: molecular evolutionary genetics analysis using maximum likelihood, evolutionary distance, and maximum parsimony methods. Mol Biol Evol 28:2731-2739

31. Drummond AJ, Rambaut A (2007) BEAST: Bayesian evolutionary analysis by sampling trees. BMC Evol Biol 7:214

32. Drummond AJ, Nicholls GK, Rodrigo AG, Solomon W (2002) Estimating mutation parameters, population history and genealogy simultaneously from temporally spaced sequence data. Genetics 161:1307-1320

33. Rambaut $A$ (2000) Estimating the rate of molecular evolution: incorporating non-contemporaneous sequences into maximum likelihood phylogenies. Bioinformatics 16:395-399

34. Hasegawa M, Kishino H, Yano T (1985) Dating of the human-ape splitting by a molecular clock of mitochondrial DNA. J Mol Evol 22:160-174

35. Drummond AJ, Ho SY, Phillips MJ, Rambaut A (2006) Relaxed phylogenetics and dating with confidence. PLoS Biol 4:e88

\section{Submit your next manuscript to BioMed Central and take full advantage of:}

- Convenient online submission

- Thorough peer review

- No space constraints or color figure charges

- Immediate publication on acceptance

- Inclusion in PubMed, CAS, Scopus and Google Scholar

- Research which is freely available for redistribution

Submit your manuscript at

www.biomedcentral.com/submit

C Biomed Central 